\title{
Indigenous Adolescent Girls' Empowerment Network (IMAGEN)
}

Kelly Hallman

Population Council

Stephanie Martinez

Follow this and additional works at: https://knowledgecommons.popcouncil.org/departments_sbsr-pgy

Part of the Demography, Population, and Ecology Commons, Family, Life Course, and Society Commons, Indigenous Studies Commons, and the International Public Health Commons How does access to this work benefit you? Let us know!

\section{Recommended Citation}

Hallman, Kelly and Stephanie Martinez. 2017. "Indigenous Adolescent Girls' Empowerment Network (IMAGEN)," IMAGEN Brief no. 1. New York: Population Council. 


\section{INDIGENOUS ADOLESCENT GIRLS' EMPOWERMENT NETWORK (IMAGEN)}

\section{IMAGINING A NETWORK FOR NATIVE GIRLS}

Adolescent Native American girls are distinct from every other segment of young people in the U.S., from the assets their ancestors have passed down to them, to the unique challenges they face as a result of historic, systemic oppression. IMAGEN seeks to equip Native-serving organizations with tools to more intentionally reach this overlooked group of girls with sustained, on-going (not merely one-off or summer-time) locally-designed programs that draw on girls' capabilities and allow them to thrive as Native persons and future leaders in their communities.

\section{RECOGNIZING THE UNIQUENESS OF GIRLS}

The Indigenous Adolescent Girls' Empowerment Network (IMAGEN) was conceived as a means of bringing together Native American-serving organizations that have the enthusiasm and capacity to adopt, document and share evidence from programs that build on Native girls' innate talents, while addressing the multiple challenges they face. The first steps towards building this network were taken during IMAGEN's inaugural workshop at the Population Council headquarters in New York City on March 7-8, 2017.

A scan conducted in preparation for the meeting of programmatic initiatives serving Native young people strongly suggested that Native youths are regarded monolithically by donors. Many programs did not differentiate the multiple human development stages between age 1024 years, opting to use wide age parameters (if any at all), and rarely distinguished the needs of girls versus boys. In short, many existing programs for Native young people are not systematically built to address the specific needs of a 10-year-old girl versus a 19-year-old boy - and this is problematic.

Identifying and working with segments of adolescent girls is a touchstone of the Population Council's Poverty, Gender, and Youth (PGY) Program, making it well-suited to partner with organizations in
LIVING WHILE GIRL \& NATIVE AMERICAN

National data and other evidence reveals the particular situation and needs of Native young people, but especially adolescent girls, in the U.S.

- According to the National Center for Education Statistics,

American Indian and Alaska Native youth rank lowest in high school graduation, falling behind their white, black, Hispanic, and Asian/Pacific Island peers (U.S. Department of Education, 20132014).

- 1 in 8 American Indian and Alaska Native youth report having been forced to have sexual intercourse (CDC, 2012).

- 1 in 3 Indian women reports having been sexually assaulted in her lifetime. These assaults are often perpetrated by nonNative attackers (Tjaden \& Thoennes, U.S. Department of Justice, 2000).

- The highest rate of teen births nationwide are found among Native girls, at a rate of 11.3 per 1,000 , versus 6.0 per 1,000 for white teens (CDC, 2014).

- Growing evidence suggests that Native girls face high risks of trafficking (Pierce, 2012). 
Indian Country that understand the significance of Native adolescent girls as a unique group for programming.

The Population Council has developed and tested a cache of tools - which can be modified by and for Native communities - for organizations seeking to more intentionally serve girls. The tools allow programs to systematically gauge within their own communities the barriers and opportunities that exist for Native adolescent girls. This was the realization and opportunity that sparked the creation of IMAGEN.

The inaugural IMAGEN workshop was attended by nine participants from six organizations covering different parts of Indian Country (see map below), including:

- The White Buffalo Calf Women's Society (WBCWS), the first women's shelter on an Indian Reservation, provides services to victims of domestic violence, sexual assault, dating violence, and stalking.

- Union Pacific Railroad's Council of Native American Heritage (CONAH), an employee group within Union Pacific that assists with recruitment, retention, and development of Native employees.

- The Appo Wicahpi/Pine Ridge Girls' School, located in the community of Porcupine, South Dakota, provides an academically rigorous program grounded in Lakota culture, language, and values.

- The Indigenous Peoples Task Force, a Native organization that provides HIV education and services to the urban Native community in Minnesota.

- The National Indigenous Women's Resource Center (NIWRC), a Native nonprofit seeking to enhance the capacity of American Indian, Alaska Native, and Native Hawaiian organizations and tribes to respond to domestic violence.
- American Indian Science and Engineering Society (AISES), a national, non-profit organization focused on increasing representation of American Indians, Alaska Natives, Native Hawaiians, Pacific Islanders and First Nations peoples in science, technology, engineering, and math (STEM) study and careers.

\section{APPLYING GLOBAL TOOLS, LOCALLY}

IMAGEN's first meeting provided a space to explore the Population Council's intentional girl program design approach. Tools were shared that allow program staff to simply and accurately assess the realities of adolescent girls in their communities and ways to tailor programs accordingly. Sessions included: Protective AssetBuilding, The Girl Roster: A Tool to Make Girls Visible, The Building Assets Exercise, and Defining Girl Segments in Your Community.

\section{LESSONS LEARNED \& NEXT STEPS}

Programs that work with Native young people in the U.S. do not appear to focus on differentiating the needs of girls versus boys, or younger versus older groups. This requires critical attention, as Native girls in the U.S. have a drastically unique risk profile that leaves them vulnerable to early pregnancy, sexual violence, trafficking and other negative health outcomes.

The enthusiasm of participants at IMAGEN's first meeting demonstrate a genuine need and willingness to advance this work. Going forward, ImAGEN will increase membership through networking and workshops in various US locations and through technical assistance to organizations wishing to more intentionally build a better future for Native adolescent girls.

\section{FOR MORE INFORMATION}

Kelly Hallman (Cherokee), PhD: khallman@popcouncil.org

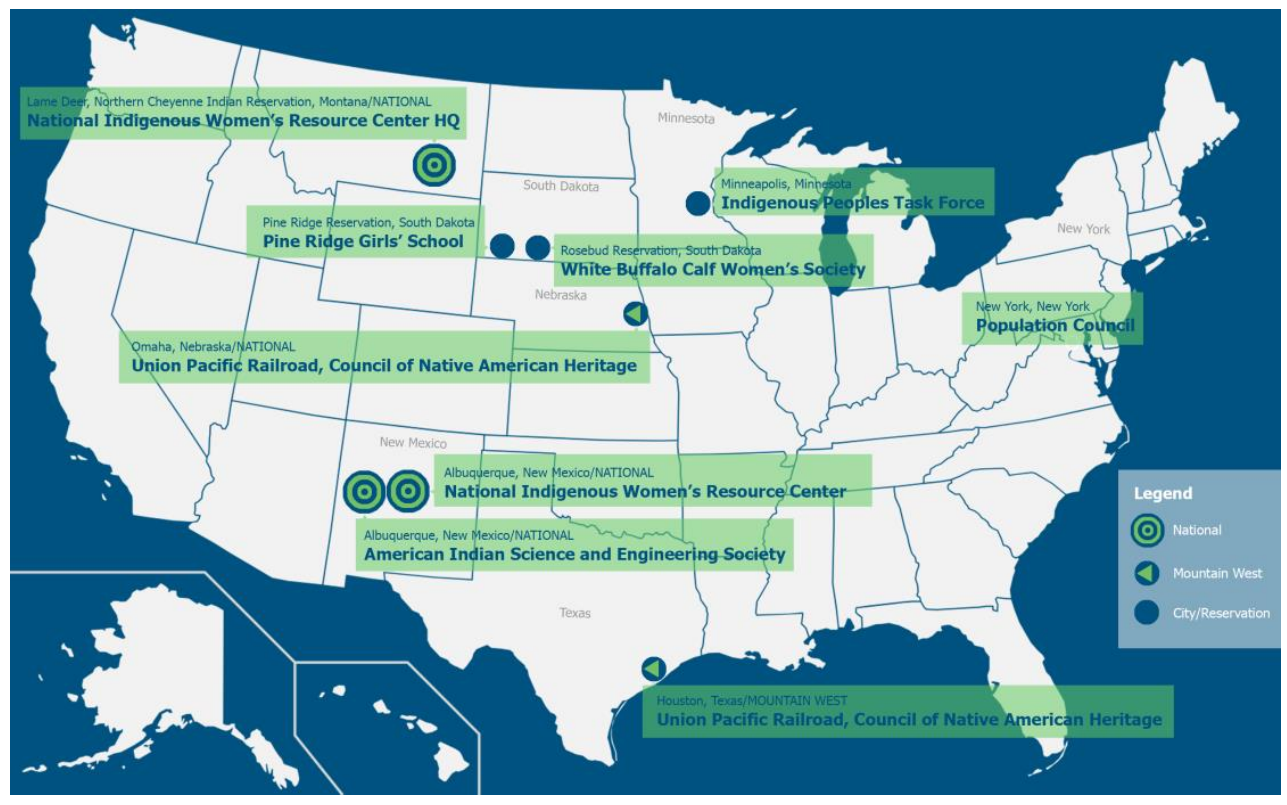

